\title{
3D Seismic Flow Units, Porosity and Permeability Modelling in Brazilian Presalt Reservoirs: An Overview
}

\author{
Rodrigo Penna ${ }^{1,2 *}$ and Wagner Moreira Lupinacci ${ }^{1}$ \\ ${ }^{1}$ GIECAR-UFF \\ ${ }^{2}$ PETROBRAS
}

\begin{abstract}
Copyright 2021, SBGf - Sociedade Brasileira de Geofísica
This paper was prepared for presentation during the $17^{\text {th }}$ International Congress of the Brazilian Geophysical Society held in Rio de Janeiro, Brazil, 16-19 August 2021.

Contents of this paper were reviewed by the Technical Committee of the $17^{\text {th }}$ International Congress of the Brazilian Geophysical Society and do not necessarily represent any position of the SBGf, its officers or members. Electronic reproduction or storage of any part of this paper for commercial purposes without the written consent of the Brazilian Geophysical Society is prohibited.
\end{abstract}

Rock typing into flow units (FU) is a well-known technique for characterizing flow heterogeneities in reservoirs and producing reliable estimations of petrophysical properties, such as porosity $(\phi)$ and permeability $(\mathrm{k})$. Despite the large availability of methods that correlates a specific pore-throat size to petrophysical attributes, extrapolating FU rock typing from the core and well-log scales into the whole reservoir is a major challenge for geophysicists, due to the scale differences between data and the lack of correlation with the common-used sedimentological facies. Most 3D generations of flow units and petrophysical properties studies available in the literature are merely a geostatistical procedure, without any spatial data constraints with the 3D seismic data. We propose a new approach to discretize flow units in the core and well-logs considering the decametric scale characteristics of the seismic data, generating a 3D model of $\mathrm{FU}$ facies and calculating porosities and permeabilities that are more accurate than the usual estimation based on sedimentary facies. Despite the complexity of the geological setting and the reduced number of FU, we produced 3D volumes of permeability and porosity that are still capable of obtaining complex reservoir flow characteristics and could be directly considered as variables in lateral interpolation of reservoir parameters, seismic 4D interpretations and seismicassisted history matching.

\section{Introduction}

For any asset team working with complex geology settings, like the Brazilian presalt carbonates province, an assertive description of the reservoir heterogeneity and flow behavior in terms of fluid movement is crucial. Considering the amount of effort and investments required to develop any presalt oil field, any calculation error present in the porosity and permeability volumes can imply Billion of dollars differences in the decision-making process. Flow units (FU) classification can present an advantage when calculating reservoir pretrophysical attributes, since it can be more accurate and generate better statical and dynamic models of the reservoir, as discussed by Daraei et al.
(2017), Hatampour et al. (2018) and Ghanbarian et al. (2019).

Flow units rarely show any correlation with lithological facies because of the nature of its classification. The incorporation of flow units into the 3D static models building process that are, in most cases, based on sedimentological premises, can be difficult. For the flow units classification, a given lithological facies deposited at a given high-energy setting can be grouped into two distinct FU facies, depending on the diagenetic history of them. However, in the sedimentary classification, they would group into the same facies. In addition, the difference in scales and the lack of correlation between well logs and seismic data makes the propagation of the petrophysical properties into 3D geological model problematic, and mostly a geostatistical approach, often resulting in non-realistic flow models. Examples of lateral extrapolations of flow units and petrophysical properties considering only well data are found, for example, in Li et al. (2018).

For geophysicists and reservoir characterization, flow units are rarely a considered technique for quantitative seismic interpretation (QSI). The main publications related to QSI (Avseth et al., 2005 and Vernik, 2016) does not mention any definition or workflow to identify and map the FU from elastic seismic attributes. Some recent works correlate flow units with multiple seismic attributes, producing constrained tridimensional petrophysical properties of porosity and permeability (e.g. Iravani et al., 2018 and Hatampour et al., 2018). However, most of the studies are simply an extrapolation of FU classification based on core and well log data into the seismic resolution, regardless of the scale difference between data types.

We propose a methodology for calculating better seismic derived petrophysical volumes, characterizing large-scale flow characteristics of the reservoir considering flow units as constraints. Using percentiles and a cumulative S-curve in permeability and porosity core measurements from the Mero Field, a Brazilian presalt carbonate reservoir (Fig.1). We calculated a small and significant number of flow units that correlates with seismic elastic attributes and respond for the large-scale flow characteristics in the reservoir, maintaining part of the local flow complexity (Penna and Lupinacci, 2020). Within each FU, we establish petrophysical relations that calculates more accurate seismic derived $3 D$ volumes of porosity and permeability and compared to volumes calculated using sedimentological k- $\phi$ relations. 


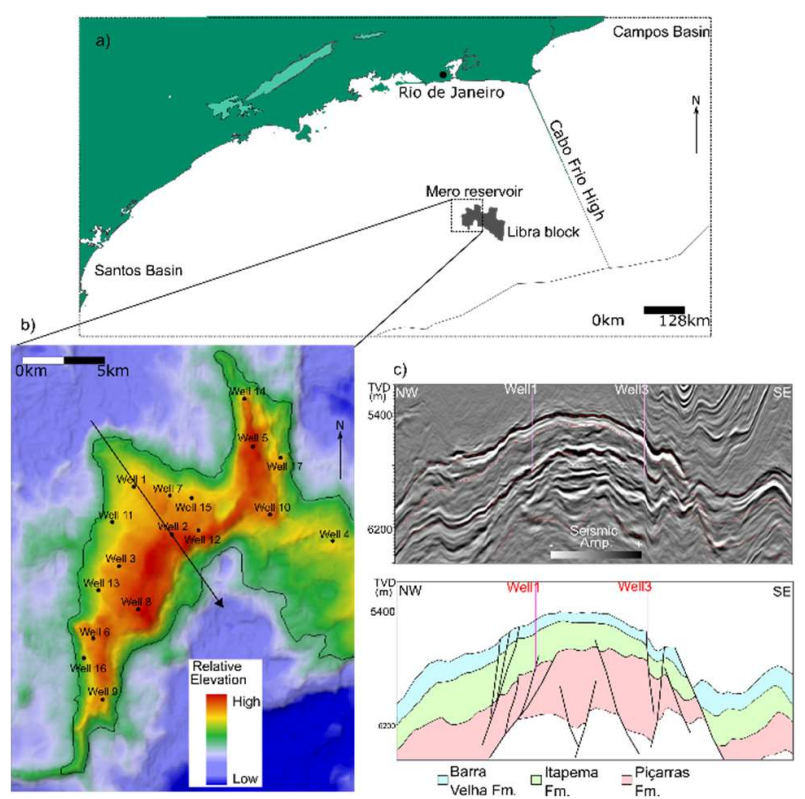

Figure1 - (a) Mero Field is located on the northeastern portion of the Santos Basin, southeast Brazil. (b) Base of salt horizon (top of the Barra Velha Formation). (c) NW-SE seismic section and interpretation of the main reservoir stratigraphy (black peak corresponds to an increasing impedance interface, white trough corresponds to a decreasing impedance interface). After Penna and Lupinacci (2021).

\section{Seismic Flow Units Rock Typing}

Given the amount of core porosity and permeability analysis available $(500 \mathrm{~m}$ of core analysis, 1700 conventional porosity and permeability measurements), we performed the FU discretization mostly based on $k$ versus $\phi$ related methods, like Gunter et al. (1997) stratigraphic modified Lorenz plot (SMLP) and flow zone indicator (FZl; Amaefule and Altunbay, 1993), who approximates a given pore-throat size radius for each FU. Other Flow Units discretization using the Lorenz S-curve and Formation Factor attributes were also performed in the 1D domain, as discussed by Penna and Lupinacci (2020).

We used the SMLP as a qualitative display to analyze the variation of flow units and fluid movement in the reservoir at different scales of observation, like stratigraphy sequence studies are made separating high order events from low order events. Fig. 2 shows four heterogeneities related to the flow units on a decametric scale, one can also notice more variations on smaller scales. In this plot, the $X$ axis is the cumulative storage capacity, and the $Y$ axis is cumulative flow capacity. Flat segments of the curve correspond to flow barriers and steep segments are the carbonates with the highest permeability and porosity.

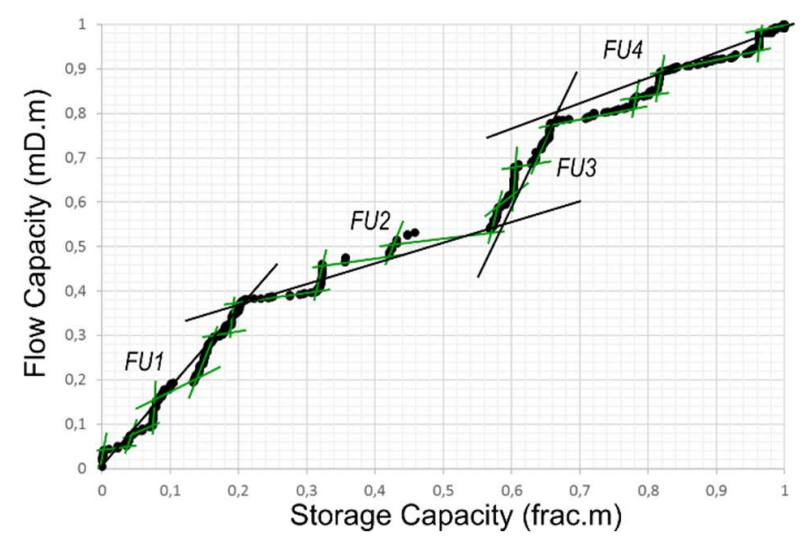

Figure 2 - SMLP and the expression of different FU in two scales of observations. Black line shows how the flow behaves in a decametric scale, while the green line shows the same in a higher scale (after Penna and Lupinacci, 2021).

Considering the construction of the SMLP curve (Fig. 2), we analyzed the cumulative porosity versus $\log (\mathrm{FZI})$ value. Fig. 3 shows how the discretization can be made in the core data, analyzing the main changes in the slope of the curve as threshold values for the rock typing, and after applied to the well log data using the $\log (\mathrm{FZI})$ values. Note that there are also four main changes in the slope, as suggested previously by the SMLP graph analysis (Fig.2). This allowed us to identify, in terms of flow movement, four FZI flow units (FU1, with worse permoporous conditions, to FU4, better), which can be latter detected in the seismic in decametric scale.

\section{Flow Units Seismic Feasibility}

To verify how the discretization of decametre flow units behaves in the elastic space, we performed a 1D feasibility study using filtered versions of well logs. Fig. 4 shows how each flow unit separates in the filtered elastic domain, considering the $\mathrm{P}$ - and $\mathrm{S}$-impedances within each $\mathrm{FZI}$ unit. FU1 tends to present higher values of impedances, while FU4 corresponds to lower values. This is expected, considering that FU1 and FU2 are mostly comprised of low porosity and silicon cemented carbonates, while FU3 and FU4 correspond to higher porosity and calcium-pure carbonates. 

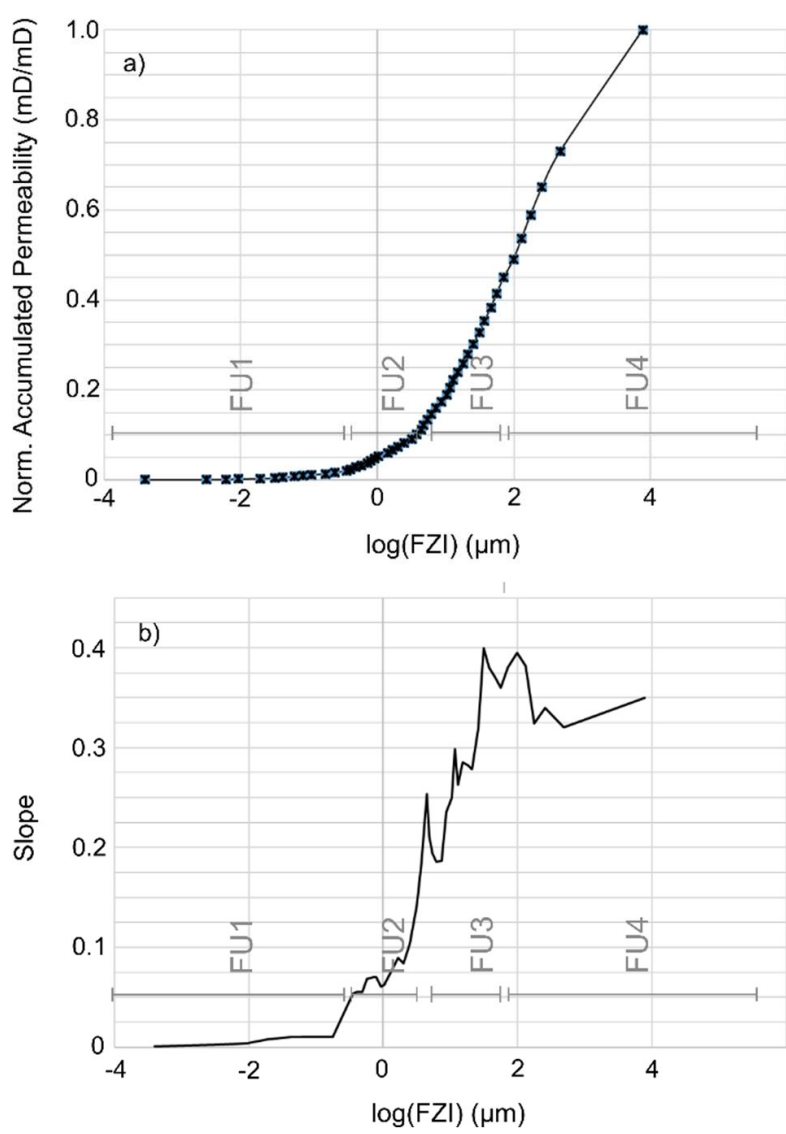

Figure 3 - Cumulative curve of permeability versus $\log (F Z I)$. Note how the four main variations shown in the SMLP (Fig.2) also appear here as high orders slope variation.

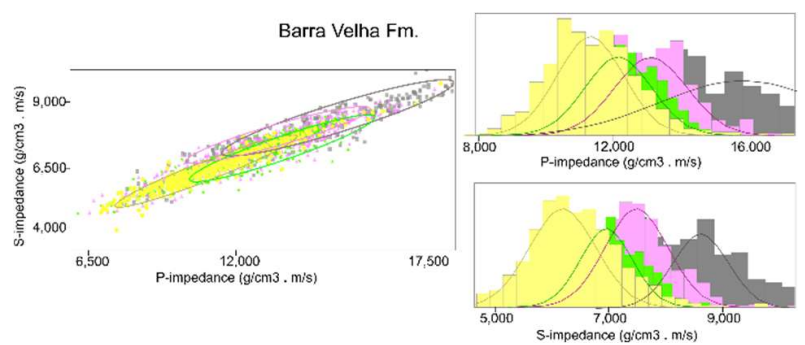

Figure 4 - Distribution of $P$ - and S-Impedances for each FU defined in Fig. 3 for the Barra Velha Fm (the Itapema Fm. shows similar distribution pattern).

One advantage of working with Flow Units to constrain the estimation of porosity and permeability is shown in Fig. 5., Flow units provide a better calculation of petrophysical parameters thanusing the seismic sedimentary facies (Penna and Lupinacci, 2021).

\section{D Bayesian Flow Units Classification}

Considering P- and S-Impedances volumes calculated through a sparse-spike prestack seismic inversion using seven partial angle stacks derived from the RTM data (Penna et al., 2019), and the probability density functions of all FU in the elastic domain (Fig.4), we performed a Bayesian classification of the volumetric occurrence probability of each flow unit. This methodology, as described by Penna and Lupinacci (2021), outputs five volumes: one discrete, called most probable FU, and four different occurrence probability volumes for each decametre flow unit. The most probable volume consists of the corresponding discrete data with the higher occurrence probability for a given sample. Each occurrence probability volume varies from zero to one, and the sum of all the probabilities for a given sample is always one.
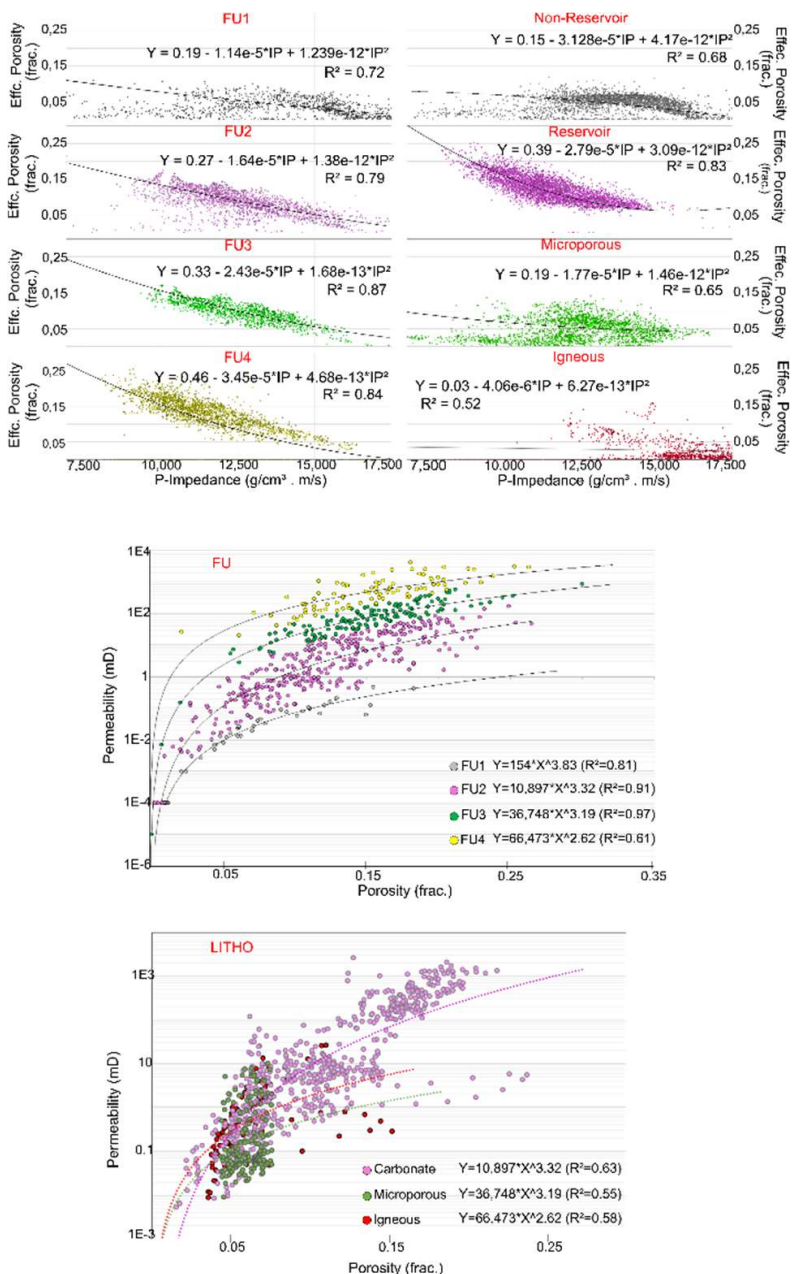

Figure 5 - Regressions of P-Impedance versus porosity (above) and porosity versus permeability (below) considering as constraints flow units and lithology facies.

\section{D Porosity and Permeability Modelling}

Fig. 6 shows the most probable facies per unit flow (upper) and for lithological facies (bottom) of the lower Barra Velha $\mathrm{Fm}$. and the respective porosity $(\phi)$ obtained from both approaches (porosity from the equations shown in Fig. 5) Fig. 7 shows the most probable facies per unit flow (upper) and for lithological facies (bottom) of the upper Itapema $\mathrm{Fm}$. and the respective permeability $(k)$ obtained from both approaches. $\phi$ and $k$ estimations using FU constraints are much more accurate than seismic lithology facies as constraint. Porosity and permeability well logs confirm this, and these results were presented in Penna and Lupinacci (2021). 

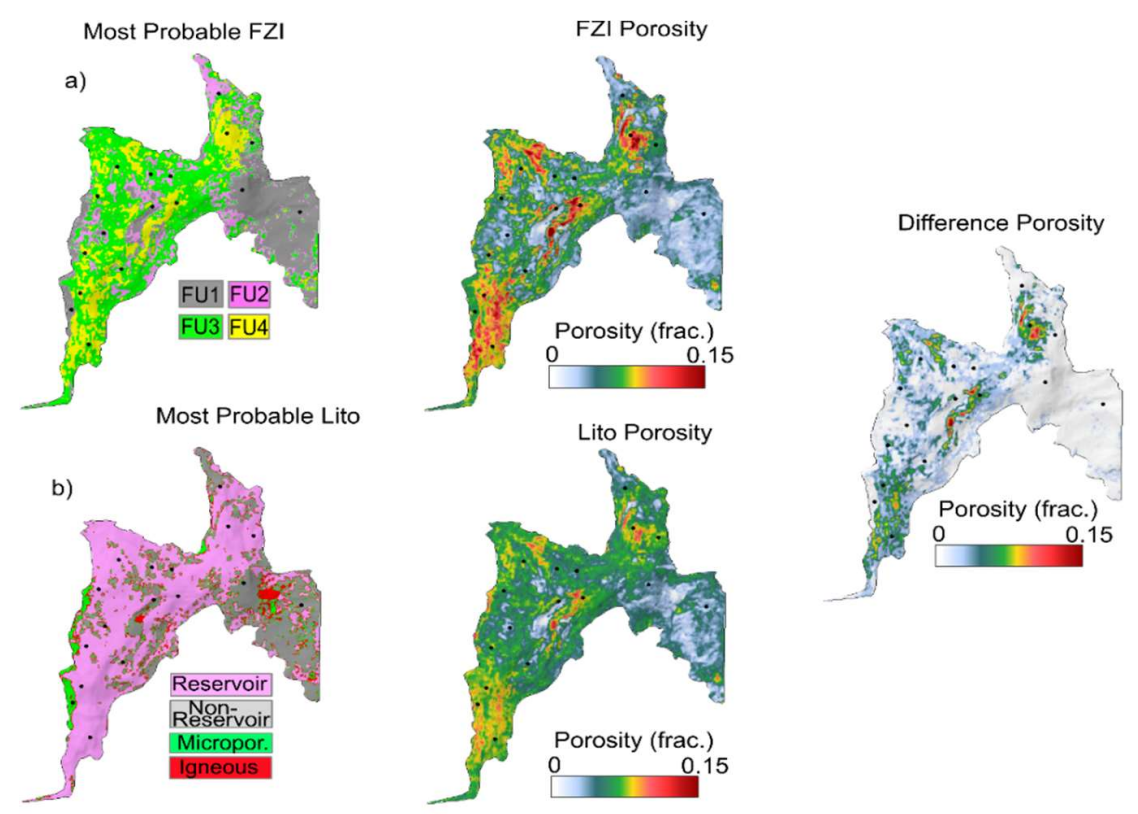

Figure 6 - (a) Lower Barra Velha Fm. FU occurrence and the corresponding estimated porosity. (b) Top of the Barra Velha Fm. most probable lithology occurrence and the corresponding estimated porosity. The differences between both estimations are displayed in the right.
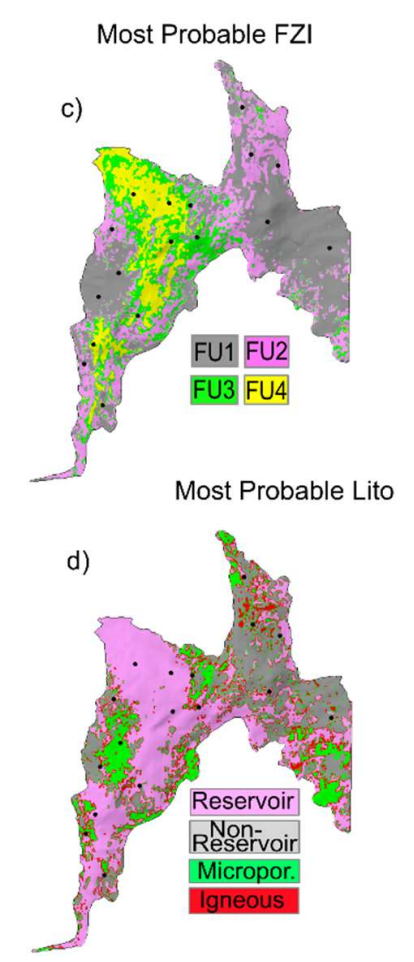

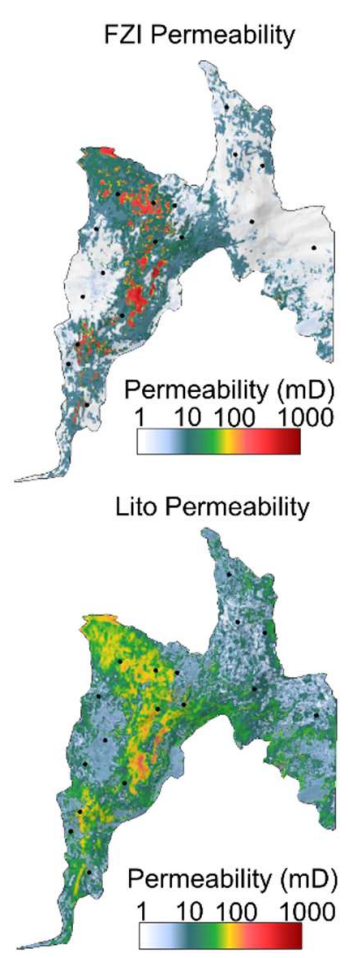

Figure 7 - (a) Upper Itapema Fm. most probable FU occurrence and the corresponding estimated permeability. (b) Top of the Itapema Fm. most probable lithology occurrence and the corresponding estimated permeability. The differences between both estimations are displayed in the right. 


\section{Conclusions}

The use of decametric flow units as a constraint to estimate petrophysical properties at seismic inversion scale produces much better results than using the lithology classification. We consider that the accurate mapping and comprehension of the flow behavior at decametric scale is the first step to build the dynamic knowledge of the reservoir at smaller scales, especially considering all the concerns and difficulties to incorporate FU into geologic models built essentially on analogs, sedimentary facies and conceptual premises. Our methodology provides ways to generate a minimum amount of FU that calculates porosity and permeability with acceptable accuracy and are correlatable with elastic attributes on seismic inversion scale.

\section{Acknowledgments}

The authors thank the Petrobras Libra JPT project and partners (Shell, Total, CNOOC and CNPC) for the data availability.

\section{References}

Amaefule, J. O. and Altunbay, M. 1993. Enhanced Reservoir Description: Using Core and Log Data to Identify Hydraulic (Flow) Units and Predict Permeability in Uncored Intervals/Wells. SPE Annual Technical Conference and Exhibition, Expanded Abstracts. SPE-26436-MS. https://doi.org/10.2118/26436-MS.

Avseth, P., Mukerji, T. and Mavko, G. 2005. Quantitative Seismic Interpretation: Applying Rock Physics Tools to Reduce Interpretation Risk. First Ed., Cambridge Press, Cambridge.

Daraei, M., Bayet-Goll, A. and Ansari, M. 2017. An Integrated Reservoir Zonation in Sequence Stratigraphic Framework: A Case from the Dezful Embayment, Zagros, Iran. Journal of Petroleum Science and Engineering. 154, 389-404. https://doi.org/10.1016/j.petrol.2017.04.038.

Ghanbarian, B., Lake, L. and Sahimi, M. 2019. Insights into Rock Typing: A Critical Study. SPE Journal. 24(1), 230242. https://doi.org/10.2118/191366-PA.

Gunter, G. W., Finneran, J. M., Hartman, D. J. and Miller, J. D. 1997. Early Determination of Reservoir Flow Units Using an Integrated Petrophysical Method. 1997 SPE Annual Technical Conference and Exhibition, SPE, Expanded Abstract, SPE 38679. https://doi.org/10.2118/38679-MS.

Hatampour, A., Schaffie, M. and Jafari, S. 2018. Hydraulic Flow Units' Estimation from Seismic Data Using Artificial Intelligence Systems, an Example from a Gas Reservoir in the Persian Gulf. Journal of Petroleum Science and Engineering. 170, 400-408. https://doi.org/10.1016/j.petrol.2018.06.086.

Iravani, M., Rastegarnia, M., Javani, D., Sanati, A. and Hajiabadi, S. H. 2018. Application of Seismic Attribute Technique to Estimate the 3D Model of Hydraulic Flow Units: A Case Study of a Gas Field in Iran. Egyptian Journal of Petroleum. 27(2), 145-157. https://doi.org/10.1016/j.ejpe.2017.02.003.
Li, P., Zheng, M., Bi, H., Wu, S., Wang, X., 2018. Pore Throat Structure and Fractal Characteristics of Tight Oil Sandstones: A Case Study in the Ordos Basin, China. J. Petrol. Sci. Eng. 149, 665-674. https://doi.org/10.1016/j.petrol.2016.11.015.

Penna, R., Araujo, S., Geisslinger, A., Sansonowski, R., Oliveira, L., Rosseto, J. and Matos, M. 2019. Carbonate and Igneous Rock Characterization Through Reprocessing, FWI Imaging and Elastic Inversion of a Legacy Seismic Data Set in Brazilian Pre-salt Province. The Leading Edge. 38(1), 11-19. https://doi.org/10.1190/tle38010011.1.

Penna, R. and Lupinacci, W., 2020. Decametre scale flow units classification in Brazilian presalt carbonates. SPE Reservoir Eval. Eng. 23 (4). SPE-201235-PA.

Penna, R. and Lupinacci, W., 2021. 3D Modelling of Flow Units and Petrophysical Properties in Brazilian Presalt Carbonate. Marine and Petroleum Geology. 124(2021).

Vernik, L. 2016. Seismic Petrophysics in Quantitative Interpretation: Society of Exploration Geophysics, Houston. 